\title{
The Influence of Temperature and Leaf Wetness Duration on Infection of Perennial Ryegrass by Rhizoctonia solani
}

\author{
M. K. Gross, Department of Botany and Plant Pathology, J. B. Santini, Department of Agronomy, and I. \\ Tikhonova and R. Latin, Department of Botany and Plant Pathology, Purdue University, West Lafayette, IN 47907
}

\begin{abstract}
Gross, M. K., Santini, J. B., Tikhonova, I., and Latin, R. 1998. The influence of temperature and leaf wetness duration on infection of perennial ryegrass by Rhizoctonia solani. Plant Dis. 82:1012-1016.

Controlled environment experiments were conducted to determine the influence of temperature and leaf wetness duration on infection of perennial ryegrass by Rhizoctonia solani. Infection of grass plants raised in pots and exposed to mycelium of $R$. solani was evaluated at various combinations of temperature and leaf wetness duration. Temperatures included 15, 18, 21, 24, and $27^{\circ} \mathrm{C}$. Leaf wetness periods were $9,12,15,18$, and $24 \mathrm{~h}$. Disease was most severe (more than 50 leaves with brown patch lesions per pot) when plants were in contact with the inoculum source for $24 \mathrm{~h}$ of leaf wetness at $24^{\circ} \mathrm{C}$. The least amount of disease $(0$ leaves with lesions per pot) occurred at $15^{\circ} \mathrm{C}$ and a 9-h wet period. The data were subjected to analysis of variance with orthogonal polynomial contrasts. Significant effects were included in a regression model that described the response of infection to temperature and wetness duration. The polynomial model included linear and quadratic terms for temperature and wetness duration. The adjusted coefficient of determination for the fitted model was 0.93 , indicating an excellent fit to the data. The model is intended for use in an improved brown patch warning system for perennial ryegrass in the midwestern United States.
\end{abstract}

Additional keywords: disease forecast, epidemiology

Rhizoctonia solani Kühn (syn. Moniliopsis solani Kühn; teleomorph Thanatephorus cucumeris) is a soil-inhabiting fungal pathogen that incites brown patch (Rhizoctonia blight), a foliar disease regarded as one of the most economically important diseases of turfgrass worldwide (24). The cool season grasses most prone to brown patch outbreaks are perennial ryegrass (Lolium perenne), creeping bentgrass (Agrostis palustris), tall fescue (Festuca arundinacea), and annual bluegrass (Poa annua) $(27,28)$.

Despite the use of cultural practices to manage the disease, strict abidance to a fungicide application schedule is relied upon for a patch-free stand, particularly on golf course greens, tees, and fairways. Fungicides are recommended when nighttime temperatures average $21^{\circ} \mathrm{C}$ and nighttime relative humidity exceeds $85 \%$ (5). In midwestern states, fungicides for brown patch control may be applied from June through August in intervals ranging from 5 to 21 days (22). Excess fungicide usage is

Corresponding author: Richard Latin

E-mail latin@btny.purdue.edu

Purdue University Agricultural Research Program Journal Article No. 15650.

Accepted for publication 3 June 1998.

Publication no. D-1998-0709-01R

(c) 1998 The American Phytopathological Society commonly associated with such calendarbased spray schedules. An ideal fungicide application program would consider factors critically associated with disease activity, and treatments would be applied when significant risk had been accurately determined. Because the pathogen is ubiquitous, with an ample host supply, the primary factor determining an outbreak of brown patch is an environment conducive to pathogen activity (19). Defining specific environmental factors most critical to disease development could serve as the template for the development of a spray advisory or disease warning system.

Attempts to define the relationship between environmental parameters and brown patch occurrence date back to Dickinson's 1930 report of correlation of disease incidence to certain irrigation patterns and temperature fluctuations (8). In 1933, Dahl reported an $82 \%$ outbreak probability on days with minimum daily temperature $\geq 21^{\circ} \mathrm{C}$ (6). More recently, Schumann et. al. (21) and Fidanza et. al. (11) have formulated environment-based brown patch predictive models that require more sophisticated environmental monitoring and interpretation. The Schumann model considers daily minimum and mean air and soil temperatures, rainfall-irrigation episodes $(>2.54 \mathrm{~mm})$, prolonged rainfall $(\geq 15 \mathrm{~mm})$, and prolonged relative humidity $(\mathrm{RH} \geq 95 \%$ for $>36 \mathrm{~h})$ in any one of three combinations to establish a high risk assessment. A field evaluation of the
Schumann model (21) demonstrated acceptable brown patch control and reduced fungicide applications to bentgrass putting greens in Massachusetts, New Jersey, and Georgia. The authors noted that thresholds for their predictive model would vary with host species and management regime, and that model modifications are necessary to increase accuracy. The Fidanza model uses mean relative humidity and minimum daily air temperature in a regression model, and bases forecasts on an environmental favorability index (E-value) generated by the regression. When field-tested for 3 years on perennial ryegrass plots in Maryland, the model predicted with $85 \%$ accuracy and resulted in a $29 \%$ reduction in fungicide applications while maintaining equal turf quality compared with the calendarbased spray plots (11). Our evaluation of the Fidanza model conducted on perennial ryegrass turf plots at Purdue University in 1996 showed that the model overpredicted brown patch occurrence throughout the summer. From 1 June through 30 September 1996, the model threshold was reached on 24 days, but brown patch pathogen activity was observed on only three of those days (R. Latin, unpublished data).

Although relative humidity is often used to represent the moisture component of predictive systems (14), actual leaf surface moisture is necessary for infection, and leaf wetness duration is a more appropriate measure of the moisture requirement for disease establishment. Although it is not included in their model, Fidanza et. al. (11) found leaf wetness duration was strongly associated with outbreaks of brown patch. The effect of temperature and leaf wetness duration is not widely used in turfgrass disease warning systems (23). The purpose of this research was to define the influence of temperature and leaf wetness duration on disease incidence on perennial ryegrass caused by $R$. solani. The results are expected to contribute to an improved disease warning model with application against brown patch on perennial ryegrass in the midwestern United States.

\section{MATERIALS AND METHODS}

Turfgrass maintenance. Perennial ryegrass (Lolium perenne) cv. Williamsburg was selected as the experimental host for all treatments. Williamsburg has a relatively high level of susceptibility to brown patch according to standard cultivar evaluations (18). Perennial ryegrass seeds 
were planted in a clay-based substrate (Turface, AIMCOR, Buffalo Grove, IL) in plastic square pots of $100 \mathrm{~cm}^{3}$ volume at a planting density of approximately 60 seeds $(0.1 \mathrm{~g})$ per pot. Turfgrass pots were placed in flats maintained in a greenhouse at Purdue University (West Lafayette, IN) and watered as needed. Hourly temperature and relative humidity were recorded in the greenhouse with a Rainwise Weatherlog (RainWise, Inc., Bar Harbor, ME) environmental sensing instrument.

Perennial ryegrass height was maintained at approximately $5 \mathrm{~cm}$ by manually cutting with scissors twice weekly. All plants were fertilized once weekly with Peters Professional All Purpose Plant Food (St. Louis, MO), a 20:20:20 water soluble fertilizer with urea as its nitrogen source. In accordance with the fertilizer label, each pot received approximately $50 \mathrm{ml}$ of fertilizer solution $(1.7 \mathrm{~g} / \mathrm{liter})$. In order to enhance brown patch susceptibility of the host $(1,4,10)$, each pot of grass was fertilized with approximately $50 \mathrm{ml}$ of solution ( $3.4 \mathrm{~g} /$ liter, double the weekly application) the day it was to be used for an experiment.

Isolation and pathogenicity. Inoculum was prepared from an isolate of $R$. solani (AG-1 IA) collected locally from infected
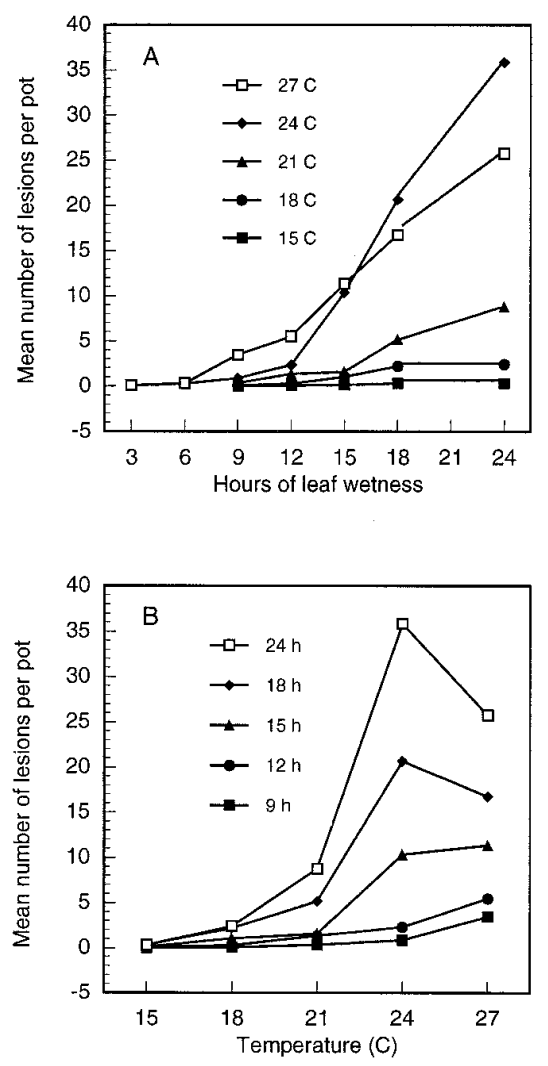

Fig. 1. The observed mean number of leaves with lesions per pot induced by Rhizoctonia solani on Lolium perenne at (A) various leaf wetness durations for each of the five temperatures tested and (B) various temperatures for each of the five leaf wetness durations. perennial ryegrass leaf tissue. White millet seed $\left(150 \mathrm{~cm}^{3}\right.$ of seed and $50 \mathrm{ml}$ of water per $500 \mathrm{ml}$ flask) was sterilized in an autoclave at $121^{\circ} \mathrm{C}$ and $7.73 \mathrm{~kg} / \mathrm{cm}^{2}$ twice over 2 days for $1 \mathrm{~h}$ each day. After the flasks were cooled, three $1 \mathrm{~cm}^{2}$ plugs of acidified potato dextrose agar (APDA) thoroughly colonized by $R$. solani were inserted into each flask under sterile conditions. Flasks with inoculated millet seed were maintained at room temperature for incubation and hand-shaken periodically.

Single square pots of 5- to 8-week-old perennial ryegrass were inoculated with $0.1 \mathrm{~g}$ of infested millet seed (or about six seeds) prepared as described above. The millet seeds were placed among the leaf blades of the grass just above the plant crowns. Pots with inoculated plants were placed in flats in a dark dew chamber where the atmosphere was saturated with moisture and the mean temperature was $27^{\circ} \mathrm{C}$ (Percival Scientific, Model I35DLM, Boone, IA). After $96 \mathrm{~h}$ in the dew chamber, the inoculated grass was covered with mycelium of $R$. solani. These plants provided an active source of inoculum for use in experiments concerning the infection response at various combinations of wetness duration and temperature.

Experiments in a controlled environment. Four square pots of healthy, densely tillered, 5- to 8-week-old perennial ryegrass were arranged around each mycelium-infested source pot so that one side of each healthy pot of grass was in direct contact with one side of the square source pot (12). Some leaf blades from each healthy pot were in direct physical contact with mycelium from the source pot. The source pot and the four uninfested pots surrounding it constituted a subsample. Three subsamples for each treatment were arranged in $28 \times 56 \mathrm{~cm}$ fiberglass flats that conveniently fit the shelves of a dew chamber (Percival Scientific, Model I35D).

Each treatment was represented by a combination of incubation temperatures and leaf wetness periods. Brown patch development was assessed at five temperatures $\left(15,18,21,24\right.$, and $\left.27^{\circ} \mathrm{C}\right)$ and five leaf wetness periods $(9,12,15,18$, and $24 \mathrm{~h}$ ). At the beginning of each run, five flats, each containing three subsamples, were placed in the dew chamber at one of the prescribed temperatures. One of the flats was removed randomly after $9 \mathrm{~h}$ in the dew chamber, another after $12 \mathrm{~h}$, a third after $15 \mathrm{~h}$, a fourth after $18 \mathrm{~h}$, and the fifth after $24 \mathrm{~h}$. Immediately following removal from the dew chamber, the source pot of each subsample was removed and each flat was moved to a greenhouse bench. Temperatures in the greenhouse ranged from 18.5 to $45^{\circ} \mathrm{C}$, and relative humidity ranged from 20 to $60 \%$. The arrangement of the five flats in the greenhouse was randomized to preclude potential effects of environmental gradients. Perennial ryegrass blades were inspected for the presence of lesions characteristic of brown patch 3 days after removal from the dew chamber. Disease severity was as-

Table 1. Analysis of variance for transformed disease severity $\left[\log _{10}(Y+1)\right]$ at 25 combinations of temperature and leaf wetness duration

\begin{tabular}{|c|c|c|c|}
\hline Source of variation & df & Mean square & $\boldsymbol{F}$ \\
\hline Temperature $(T)$ & 4 & 7.9966 & $67.43 * * a$ \\
\hline$T$-linear (l) & 1 & 31.0820 & $262.12 * *$ \\
\hline$T$-quadratic (qd) & 1 & 0.0003 & 0.00 \\
\hline$T$-cubic (c) & 1 & 0.5503 & 4.64 \\
\hline$T$-quartic (qr) & 1 & 0.3538 & 2.98 \\
\hline Error (a) & 10 & 0.1186 & $2.72 *$ \\
\hline Hours of wetness $(W)$ & 4 & 3.8692 & $88.79 * *$ \\
\hline$W$-linear (1) & 1 & 14.7752 & $338.88 * *$ \\
\hline$W$-quadratic (qd) & 1 & 0.4204 & $9.65 * *$ \\
\hline$W$-cubic (c) & 1 & 0.2793 & $6.41 *$ \\
\hline$W$-quartic (qr) & 1 & 0.0020 & 0.05 \\
\hline$T \times W$ & 16 & 0.3315 & $7.61 * *$ \\
\hline$T-1 \times W-1$ & 1 & 2.6359 & $60.49 * *$ \\
\hline$T-1 \times W$-qd & 1 & 0.1220 & 2.80 \\
\hline$T-1 \times W-\mathrm{c}$ & 1 & 0.0108 & 0.25 \\
\hline$T-1 \times W$-qr & 1 & 0.0360 & 0.83 \\
\hline$T-\mathrm{qd} \times W-1$ & 1 & 1.2750 & $29.26 * *$ \\
\hline$T$-qd $\times W$-qd & 1 & 0.0017 & 0.04 \\
\hline$T-\mathrm{qd} \times W-\mathrm{c}$ & 1 & 0.0287 & 0.66 \\
\hline$T$-qd $\times W$-qr & 1 & 0.0485 & 1.11 \\
\hline$T-\mathrm{c} \times W-1$ & 1 & 0.5413 & $12.42 * *$ \\
\hline$T$-c $\times W$-qd & 1 & 0.0517 & 1.19 \\
\hline$T-\mathrm{c} \times W-\mathrm{c}$ & 1 & 0.0056 & 0.13 \\
\hline$T-\mathrm{cc} \times W$-qr & 1 & 0.0089 & 0.20 \\
\hline$T-\mathrm{qr} \times W-1$ & 1 & 0.1546 & 3.55 \\
\hline$T$-qr $\times W$-qd & 1 & 0.1544 & 3.54 \\
\hline$T$-gr $\times W$-c & 1 & 0.0248 & 0.57 \\
\hline$T$-qr $\times W$-qr & 1 & 0.2040 & $4.68 *$ \\
\hline Error (b) & 40 & 0.0436 & $5.67 * *$ \\
\hline Sampling error & 150 & 0.0077 & \\
\hline
\end{tabular}

a *,** significant at 0.05 and 0.01 , respectively. 
sessed by counting the number of leaf blades with characteristic brown patch lesions for each pot (abbrev.: leaves with lesions per pot). The mean number of leaves with lesions per pot $(Y)$ averaged across the four pots was determined for each subsample. Lesions that were not typical of brown patch symptoms were removed and cultured on APDA to determine if infection had occurred.

The experiment was a split-plot design with the whole-unit treatments arranged in a completely randomized design (25). The whole-unit treatments were the different levels of temperature and were replicated three times, in time, in completely random order using a single dew chamber. The subunit treatments were the different hours of leaf wetness and were randomized within every whole unit. Three subsamples were observed in every subunit.

In a separate but related experiment with a similar experimental design including three whole-unit replicates, 3- and 6-h leaf wetness duration treatments were conducted at 24 and $27^{\circ} \mathrm{C}$. These were the temperatures at which lesions developed

Table 2. Estimated parameters for equation 2 relating the severity of brown patch on perennial ryegrass to temperature and leaf wetness duration

\begin{tabular}{lrc}
\hline Parameter & $\begin{array}{c}\text { Parameter } \\
\text { estimate }\end{array}$ & $\begin{array}{c}\text { Standard } \\
\text { error }\end{array}$ \\
\hline$b_{0}$ & 5.544089 & 2.30684297 \\
$b_{1}$ & -0.627193 & 0.22482657 \\
$b_{2}$ & 0.015183 & 0.00533400 \\
$b_{3}$ & -0.404894 & 0.14369276 \\
$b_{4}$ & -0.001773 & 0.00103479 \\
$b_{5}$ & 0.045619 & 0.01368251 \\
$b_{6}$ & -0.000968 & 0.00032462 \\
\hline
\end{tabular}

after $9 \mathrm{~h}$ of leaf wetness. If no lesions were observed in pots that spent $9 \mathrm{~h}$ in the saturated atmosphere (as occurred at 15, 18, and $21^{\circ} \mathrm{C}$ ), then disease severity for the 3 and 6-h treatments was assumed to be zero.

Data analysis and model development. All statistical analyses were carried out using procedures by SAS. (SAS Institute, Cary, NC). A Box-Cox evaluation was applied to the disease severity data $(Y)$ prior to other analyses (2). The linear regression of the $\log$ of the standard deviation of $Y$ across 45 observations (3 subsamples $\times 3$ replicates $\times 5$ temperatures) on the log of the mean of $Y$ at each level of leaf wetness duration was significant, with a slope near 1, suggesting a logarithmic transformation would provide the most homogeneous error variance. Disease severity data were transformed to $\log _{10}(Y+$ 1) for further analysis. One was added to the raw $Y$ value to prevent the occurrence of $\log _{10}(0)$.

In order to define the influence of temperature and leaf wetness duration on transformed disease severity $\left[\log _{10}(Y+1)\right]$, analysis of variance (ANOVA) and multiple regression procedures were applied to the data. Sums of squares for temperature $(T)$, hours of leaf wetness duration $(W)$, and their interaction $(T \times W)$ were partitioned into orthogonal polynomial contrasts using coefficients computed by the SAS (IML) ORPOL function. The linear model describing the experimental design for analysis of variance was the following:

$Y_{i j k l}=\mu+T_{i}+a_{(i) j}+W_{k}+T W_{i k}+b_{(i j k)}+\delta_{(i j k) l}$ (1)

where $Y_{i j k l}$ is the response of the ijklth individual subunit; $\mu$ is the overall mean; $T_{i}$ is the effect of the $i$ th temperature (fixed), $i$ $=1, \ldots, 5 ; a_{(i) j}$ is the random effect (error) of the $j$ th whole unit for the $i$ th temperature level; $W_{k}$ is the effect of $k$ th level of leaf wetness (fixed), $k=1, \ldots, 5 ; T W_{i k}$ is the interaction of the $i$ th temperature with the $k$ th wetness duration; $b_{(i j k)}$ is the random effect (error) of the $i j k$ th subunit; and $\delta_{(i j k) l}$ is the random effect (error) of the $l$ th subunit in the ijkth combination, $l=1,2,3$. Regression models were developed for the 25 treatment means using the SAS regression procedure (REG) to formulate the surface response, based on the significant orthogonal polynomial contrasts. The $95 \%$ confidence intervals about predicted means on the predicted response surface were derived by adjusting the regression-based confidence limits with the appropriate standard error for making a particular comparison based on the error terms from the analysis of variance (9).

\section{RESULTS}

There was an overall trend for disease severity to increase as hours of leaf wetness increased for all temperatures tested (Fig. 1A). The trend was similar as temperature increased for all hours of leaf wetness tested, with the exception of a decrease in disease severity for 18- and 24$\mathrm{h}$ treatments as temperature increased from 24 to $27^{\circ} \mathrm{C}$ (Fig. 1B). The observed number of leaves with lesions per pot for any one subsample over all treatments ranged between 0 and 52, with the lowest count (0) occurring at least once at all temperatures for $9 \mathrm{~h}$ and also for longer leaf wetness durations at the lower temperatures $\left(15,18,21^{\circ} \mathrm{C}\right)$. The highest count occurred at $24^{\circ} \mathrm{C}$ and $24-\mathrm{h}$ leaf wetness duration. For the 24 and $27^{\circ} \mathrm{C}$ treatments, disease severity was greater than zero at $9 \mathrm{~h}$ of leaf wetness, and therefore 3- and 6-h leaf wet-
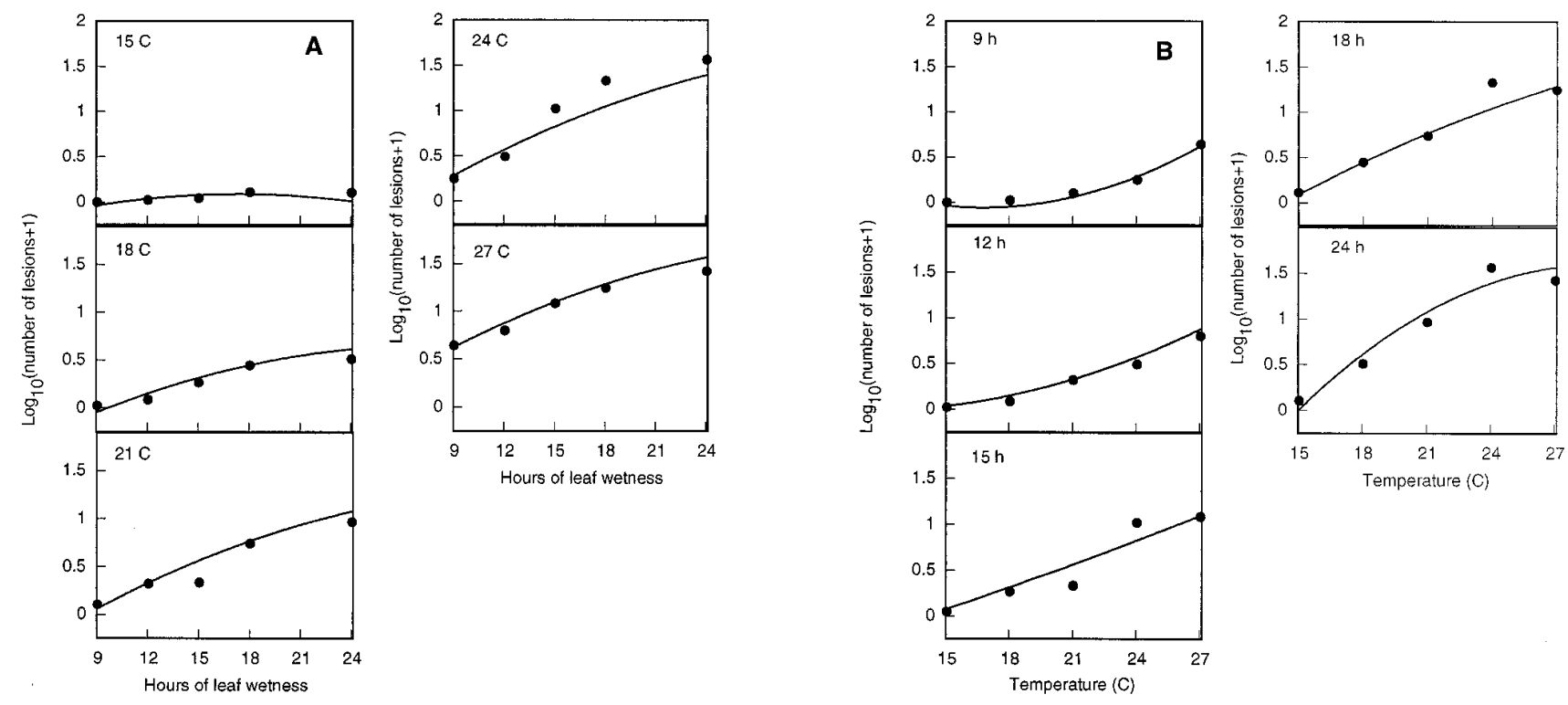

Fig. 2. Observed and predicted mean disease severity $\left[\log _{10}(\right.$ number of leaves with lesions +1$\left.)\right]$ at $(\mathbf{A})$ various leaf wetness durations for each of the five temperatures tested, and (B) various temperatures for each of the five leaf wetness durations treatments. The solid lines in each graph were generated by the polynomial model described in equation 2 and parameter estimates listed in Table 2. The data points represent the mean $\log _{10}$ (number of leaves with lesions + 1). 
ness duration treatments were also evaluated at those temperatures. At both temperatures, no more than one lesion was counted in any subsample for the 6- and 3$\mathrm{h}$ treatments.

The polynomial model. The analysis of variance showed a highly significant $(P<$ $0.01)$ linear relationship between $\log _{10}(Y+$ $1)$ and temperature $(T)$ averaged across leaf wetness (Table 1). It also showed highly significant linear and quadratic relationships between $\log _{10}(Y+1)$ and hours of leaf wetness $(W)$ averaged across temperature, while the cubic effect was significant $(P<0.05)$. The $T$-linear $\times W$-linear, $T$-quadratic $\times W$-linear, and $T$-cubic $\times$ $W$-linear were also highly significant, while $T$-quartic $\times W$-quartic was significant. Several regression models using the 25 treatment means were evaluated. Models containing the $T$-quartic $\times W$-quartic, $T$ cubic $\times W$-linear, and $W$-cubic effects were rejected because they produced response surfaces that showed a decrease in disease severity from 24 to $27^{\circ} \mathrm{C}$ at both 18 - and 24-h leaf wetness durations. Although such a response surface is reflective of our observed data (Fig. 1B), brown patch, a warm weather disease, is unlikely to decrease as temperature rises in the field. We thus concluded that the quadratic model, which omitted the effects that produced an unrealistic decrease in disease severity, made the most sense biologically.

The influence of temperature and hours of leaf wetness on brown patch severity can be described by the following polynomial regression model:

$$
\begin{aligned}
\log _{10}(Y+1)= & b_{0}+b_{1} T+b_{2} T^{2}+b_{3} W+b_{4} W^{2} \\
& +b_{5} T W+b_{6} T^{2} W
\end{aligned}
$$

where $Y$ is disease severity (the mean number of leaves with lesions per pot), $T$ is temperature $\left({ }^{\circ} \mathrm{C}\right)$, and $W$ is leaf wetness duration (hours). The $b$ values are the estimates of the partial regression coefficients and are listed in Table 2. The $R$ square and the adjusted $R$-square were 0.95 and 0.93 , respectively. The model mean square was 0.9294 , and the error mean square was 0.0159 . Figures $2 \mathrm{~A}$ and $\mathrm{B}$ demonstrate how the curves generated by the polynomial model fit the observed means at each temperature and leaf wetness duration period.

Figures $3 \mathrm{~A}$ and B show the predicted regression response surface at selected leaf temperatures and wetness durations. The predicted $\log _{10}$ (number of leaves with lesions +1 ) as a function of the wetness duration (Fig. 3A) generally increased with time, although there was no significant response at $15^{\circ} \mathrm{C}$. The predicted $\log _{10}$ (number of leaves with lesions +1 ) as a function of temperature (Fig. 3B) generally increased with temperature, but was noticeably concave at $9 \mathrm{~h}$ and noticeably convex at $24 \mathrm{~h}$. Overall, $\log _{10}(Y+1)$ increased as temperature increased for all wetness duration periods and also increased as wetness duration periods increased for all temperatures except $15^{\circ} \mathrm{C}$ (Fig. $3 \mathrm{~A}$ and B). The response surface of the polynomial model is depicted in Figure 4.

\section{DISCUSSION}

The polynomial model adopted to describe our data is similar in design to models developed to forecast outbreaks of Alternaria leaf blight on muskmelon (9) and anthracnose on watermelon (17), both of which are incorporated into the Melcast disease warning system (16). The analysis of variance allowed the variables in our model to be selected directly from the significant ANOVA orthogonal polynomial contrasts, rather than using regression as an exploratory tool to build the model. As indicated by the high $R^{2}$ value, the variability among the observed mean $\log _{10}$ (number of leaves with lesions +1 ) was largely accounted for by the components in the polynomial model. Although the $T$ cubic $\times W$-linear effect was highly significant (Table 1), we rejected incorporating this interaction and the other significant cubic interactions into the model. Rejected
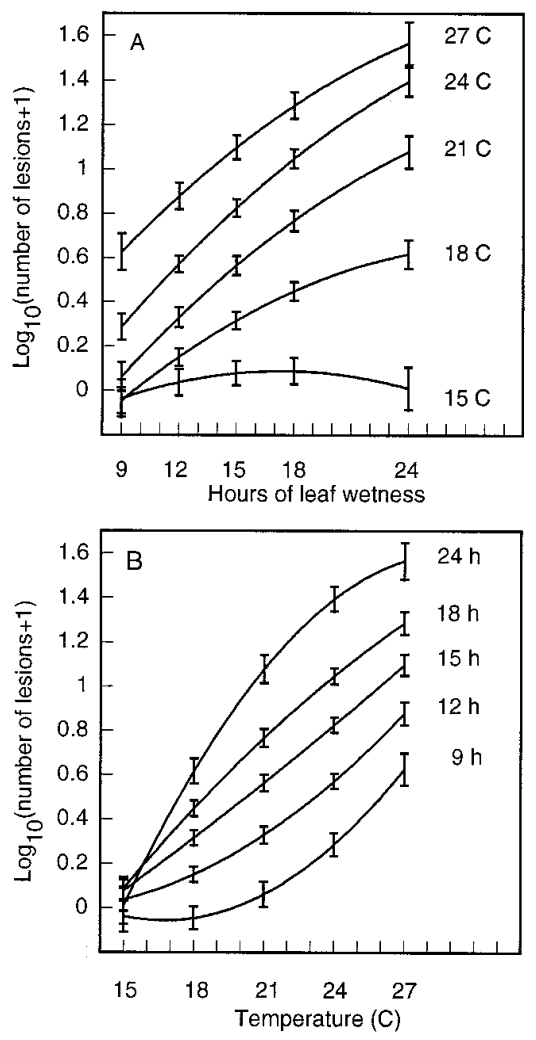

Fig. 3. $\log _{10}$ (number of leaves with lesions + 1) as a function of leaf wetness duration at various temperatures (A) and as a function of temperature at various leaf wetness durations (B). The error bars are the $95 \%$ confidence intervals for the predicted means. The error bars for Figure 3A compare predicted means at different temperatures within the same leaf wetness duration, while the error bars for Fig 3B compare predicted means at different leaf wetness durations within the same temperature. models also provided an excellent fit to the data but did not generate a surface response reflective of what we would expect from brown patch in the field. Specifically, we would not expect disease severity of brown patch to decline as temperature increased from 24 to $27^{\circ} \mathrm{C}$ for the 18 - and 24-h leaf wetness treatments. Perhaps the decrease in disease severity occurred because our particular isolate is sensitive to the higher temperature. Because brown patch occurrence is quite common at $27^{\circ} \mathrm{C}$ in the midwestern United States, we opted for the more conservative quadratic model.

The model demonstrates that temperature and leaf wetness duration are significant determinants of brown patch infection on perennial ryegrass. The overall increased lesion incidence with increased temperature and leaf wetness duration coincided with other reports of such environmental variables regulating fungal pathogen activity in general $(7,9,13,15,17)$ as well as $R$. solani specifically (20). Rowley (20), for example, showed that some isolates infected turf at $12^{\circ} \mathrm{C}$, provided that leaf wetness duration was at least $8 \mathrm{~h}$. The isolate of $R$. solani used in this research was collected locally from infected perennial ryegrass. Isolates of $R$. solani that cause brown patch on warm season grasses are not likely to behave similarly. They tend to infect at cooler temperatures $\left(<20^{\circ} \mathrm{C}\right)$ and occur in spring and fall rather than summer (3). Therefore, our model describing the influence of temperature and leaf wetness duration on infection by $R$. solani is not likely applicable to brown patch on warm season grasses.

Our results show that the effects of temperature were more pronounced at the longer wetness duration periods than at the shorter periods, indicating, as suggested by Lalancette et. al. (15), that leaf wetness is perhaps the environmental variable that permits an infection event, but temperature determines the rapidity and extent of that event.

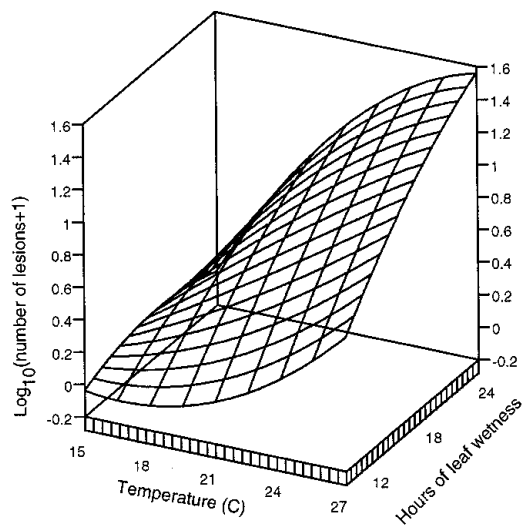

Fig. 4. A surface response based on the polynomial model (equation 2) describing the influence of temperature and leaf wetness duration on infection of perennial ryegrass by Rhizoctonia solani. 
According to our model, the greatest disease spread was at $27^{\circ} \mathrm{C}$ and $24 \mathrm{~h}$ of leaf wetness. This corresponds to the findings of the Schumann model (21) and by Vallencourt and Schumann (26) that severe brown patch outbreaks occur when the average daily temperature is greater than $21^{\circ} \mathrm{C}$ and $\mathrm{RH}$ is $>95 \%$ for at least $12 \mathrm{~h}$. Although $R$. solani tends to be associated with optimal infection temperatures closer to 27 to $28^{\circ} \mathrm{C}(5,8,21)$, optimal infection temperatures among the many strains of $R$. solani are known to range from 21 to $32^{\circ} \mathrm{C}$ (24).

Although $R$. solani activity at temperatures above $30^{\circ} \mathrm{C}$ has been reported (6), several factors led to the decision to use $27^{\circ} \mathrm{C}$ as the highest temperature. Maintaining temperatures greater than $27^{\circ} \mathrm{C}$ in controlled environment chambers is difficult and strains the limits of the chamber. Also, prolonged wetness periods (greater than $1 \mathrm{~h}$ or so) at such temperatures are extremely unusual in the midwestern United States. Finally, further experiments at temperatures greater that $27^{\circ} \mathrm{C}$ need not be run in order to meet the objective of the model. Unnecessary fungicide applications are most likely to occur during the late spring/early summer when temperature alone is an unreliable indication of a brown patch outbreak, and the turf manager chooses to assume the threat exists. At this time, a fine-tuned empirical understanding of the relationships among temperature, leaf wetness duration, and disease may improve decision making regarding fungicide applications.

The influence of temperature and leaf wetness duration on brown patch infection may behave differently in the field than in the controlled environment (13). The proposed model will therefore be field-tested and perhaps modified in the near future. As proposed by Fidanza et. al. (11), it is likely that minimum daily air temperature may play a key factor in finalizing model parameters.

Perhaps because superintendents and managers doubt the accuracy of today's disease forecasters, disease forecaster popularity is not widespread in the turf industry. As the future brings advanced weather-monitoring and computer-modeling technology, as well as increased pesticide restrictions, managers of turfgrass will be more inclined, or perhaps required, to invest in such a management tool.

\section{LITERATURE CITED}

1. Bloom, J. R., and Couch, H. B. 1960. Influence of environment on diseases of turfgrasses. I. Effect of nutrition, $\mathrm{pH}$, and soil moisture on Rhizoctonia brown patch. Phytopathology 50:532-534.

2. Box, G. E. P., Hunter, W. G., and Hunter, J. S. 1978. Statistics for Experimenters: An Introduction to Design Data Analysis, and Model Building. John Wiley \& Sons, New York. pp. 232-241.

3. Burpee, L., and Martin, B. 1992. Biology of Rhizoctonia species associated with turfgrass. Plant Dis. 76:112-117.

4. Burpee, L. L. 1995. Interactions among mowing height, nitrogen fertility, and cultivar affect the severity of Rhizoctonia blight of tall fescue. Plant Dis. 79:721-726.

5. Couch, H. B. 1995. Rhizoctonia blight of cool season turfgrasses. Pages 59-64 in: Diseases of Turfgrasses. Kreiger Publishing Co., Malabar, IL.

6. Dahl, A. S. 1933. Effect of temperature on brown patch of turf. Phytopathology 23:8.

7. Danneberger, T. K., Vargas, J. M., Jr., and Jones, A. L. 1984. A model for weather-based forecasting of anthracnose on annual bluegrass. Phytopathology 74:448-451.

8. Dickinson, L. S. 1930. The effect of air temperature on the pathogenicity of Rhizoctonia solani parasitizing grasses on putting-green turf. Phytopathology 20:597-608.

9. Evans, K. J., Nyquist, W. E., and Latin, R. X. 1992. A model based on temperature and leaf wetness duration for establishment of Alternaria leaf blight of muskmelon. Phytopathology 82:890-895.

10. Fidanza, M. A., and Dernoeden, P. H. 1996. Interaction of nitrogen source, application timing, and fungicide on Rhizoctonia blight in ryegrass. HortScience 31(3):389-392.

11. Fidanza, M. A., Dernoeden, P. H., and Grybauskas, A. P. 1996. Development and field validation of a brown patch warning model for perennial ryegrass turf. Phytopathology 86:385-390

12. Giesler, L. J., Yuen, G. Y., and Horst, G. L. 1996. The microclimate in tall fescue turf as affected by canopy density and its influence on brown patch disease. Plant Dis. 80:389-394.

13. Grove, G. G., Madden, L. V., Ellis, M. A., and Schmitthenner, A. F. 1985. Influence of temperature and wetness duration on infection of immature strawberry fruit by Phytophthora cactorum. Phytopathology 75:165-169.

14. Jones, A. L. 1986. Role of wet periods in predicting foliar diseases. Pages 87-99 in Plant Disease Epidemiology, Population Dynamics and Management. Vol. 1. K. J. Leonard and W. E. Fry, eds. Macmillan Publishing, New York.

15. Lalancette, N., Ellis, M. A., and Madden, L. V. 1988. Development of an infection efficiency model for Plasmopara viticola on American grape based on temperature and duration of leaf wetness. Phytopathology 78:794-800.

16. Latin, R., and Evans, K. J. 1996. Development and delivery of a forecaster for Alternaria leaf blight of muskmelon. (Abstr.) Phytopathology 86:S106.

17. Monroe, J. S., Santini, J. B., and Latin, R. 1997. A model defining the relationship between temperature and leaf wetness duration, and infection of watermelon by Colletotrichum orbiculare. Plant Dis. 81:739-742.

18. National Perennial Ryegrass Test, Final Report 1991-94, NTEP (National Turfgrass Evaluation Program) No. 95-12. U.S. Dep. Agric. Agric. Res. Serv.

19. Nutter, F. W., Cole, H., Jr., and Schein, R. D. 1983. Disease forecasting system for warm weather Pythium blight of turfgrass. Plant Dis. 67:1126-1128.

20. Rowley, L. V. 1991. Applied epidemiology of Rhizoctonia spp. on Turfgrass. MS thesis. University of Massachusetts, Amherst.

21. Schumann, G. L., Clarke, B. B., Rowley, L. V., and Burpee, L. L. 1994. Use of environmental parameters and immunoassays to predict Rhizoctonia blight and schedule fungicide applications on creeping bentgrass Crop Prot. 13:211-218.

22. Schurtleff, M. C., Fermanian, T. W., and Randell, R. 1987. Controlling Turfgrass Pests. Prentice-Hall, Englewood Cliff, NJ.

23. Shane, W. W. 1994. Use of Disease Models for Turfgrass Management Decisions. Pages 397-404 in: Handbook of Integrated Pest Management for Turf and Ornamentals. Lewis Publishers, Boca Raton, FL.

24. Smiley, R. W., Dernoeden, P. H., and Clarke, B. B. 1992. Compendium of Turfgrass Diseases. 2nd ed. American Phytopathological Society, St. Paul, MN.

25. Steel, R. G. D., Torrie, J. H., and Dickey, D. A. 1997. Principles and Procedures of Statistics: A Biometrical Approach. 3rd ed. McGraw-Hill, New York. p. 402.

26. Vallencourt, L., and Schumann, G. L. 1991 Preliminary model for predicting brown patch (Rhizoctonia spp.) on creeping bentgrass. (Abstr.) Phytopathology 81:125.

27. Vargas, J. M. 1994. Management of Turfgrass Diseases. 2nd ed. Lewis Publishers, Boca Raton, FL.

28. Watschke, T. L., Dernoeden, P. H., and Shetlar, D. J. 1995. Managing Turfgrass Pests. Lewis Publishers, Boca Raton, FL. 